ISSN: 0212-5099

DOI: https://doi.org/10.24310/BAETICA.2018.v0i38.5270

\title{
DE HIDALGOS A CABALLEROS, DE ARTESANOS A OLIGARCAS. LA TRAYECTORIA SOCIAL DE LOS GÁLVEZ (ANTEQUERA, 1700-1870)
}

\author{
Francisco Hidalgo Fernández* \\ Universidad DE MÁlaga
}

\begin{abstract}
RESUMEN
El estudio de las oligarquías urbanas es un tema de gran interés entre la historiografía española. Trabajos desde la historia política y social han incidido en conocer la procedencia de aquellos personajes que ostentaron el poder local durante la Edad Moderna. Sin embargo, Antequera presenta un panorama desolador referente a los estudios sobre sus familias principales. Pretendemos analizar la proyección de la familia Gálvez entre los siglos XVIII y XIX, observando su proceso de ascenso social, desde unas posiciones limítrofes hasta su escala entre los peldaños de la nobleza. Una posición en la que permanecieron a pesar de los cambios político-administrativos del sistema liberal español.
\end{abstract}

PALABRAS CLAVE: Antequera, Edad Moderna, familia, oligarquía, ascenso social

*frhifer@uma.es

(C) Baetica. Estudios Historia Moderna y Contemporánea, 38, 2018, 159-191. Facultad de Filosofía y Letras, Universidad de Málaga. Departamento de Historia Moderna y Contemporánea 


\title{
FROM HIDALGOS TO KNIGHTS, FROM ARTISANS TO OLIGARCHS. THE SOCIAL TRAJECTORY OF THE GÁLVEZ (ANTEQUERA, 1700-1870)
}

\author{
Francisco Hidalgo Fernández* \\ Universidad DE MÁlaga
}

\begin{abstract}
The study of urban oligarchies is a subject of great interest among Spanish historiography. The works of political and social history have an impact on knowing the origin of the characters that manifest local power during the Modern Age. However, Antequera presents a bleak panorama concerning the studies on their main families. We intend to analyze the projection of the Gálvez family between the 18th and 19th centuries, observing its process of social ascent, from the limited positions to its scale by the steps of the nobility. A position in which they remained despite the political-administrative changes of the Spanish liberal system.
\end{abstract}

KEYWORDS: Antequera, Modern Age, family, oligarchy, upward mobility 


\section{INTRODUCCIÓN}

Los años comprendidos entre 1789 y 1808 han sido vistos por parte de la historiografía más tradicional como un momento de ruptura entre dos modelos: el antiguo-regimental y el liberal; un cambio que ha supuesto habitualmente el freno o el punto final de algunas investigaciones ante el advenimiento de las referidas fechas. Sin embargo, como ha quedado atestiguado, lo cierto es que, si bien se produjeron modificaciones en cuanto a las estructuras económicas o, a priori, políticas, la sociedad continuó cumpliendo con unos modelos de vida que sólo fueron alterándose con el transcurrir de la centuria decimonónica.

El objetivo del presente estudio es analizar la trayectoria de la familia Gálvez, radicada en Antequera desde las postrimerías del siglo XVII, en su proceso de ascenso social, analizando cuáles fueron las estrategias seguidas en los enlaces matrimoniales; cuál fue la base de su crecimiento económico; y cómo llegaron a posicionarse entre la oligarquía de la ciudad, observando a su vez cómo dicho apellido permanece vinculado con la actividad del cabildo municipal durante el siglo XVIII y en momentos avanzados del ulterior ${ }^{1}$.

Asimismo, y puesto que ya otros trabajos han tocado parte de los temas que aquí tratamos, uno de los elementos más innovadores del presente va a ser su localización geográfica. Antequera, pese a su relevancia dentro de la España meridional, no ha sido partícipe de averiguaciones acerca de su entramado social, destacando tan sólo las páginas redactadas por Parejo Barranco en los años $80^{2}$ o, ya a finales de los 90, el capítulo destinado a las élites locales antequeranas durante el siglo XIX por el mismo autor ${ }^{3}$. Poco más se puede nombrar ${ }^{4}$.

Frente a esta ausencia casi total de estudios sobre aquellos que compusieron el gobierno local, la historiografía española e, incluso, malagueña va a contribuir a aportar luz a las hipótesis que se plantearán. En el caso

1. Un periodo de cambio que nos permite hablar de la creación de unas trayectorias de la incertidumbre, como explica García González, es decir, el devenir de gentes anónimas, en contraposición a las biografías normadas. F. García GonzÁlez (2007), 96.

2. J. A. Parejo Barranco (1985).

3. J. A. Parejo Barranco (1998).

4. Destacamos aquí otros dos trabajos, referentes al linaje Gálvez, ambos en prensa, uno dirigido hacia la trayectoria de la familia, en una línea distinta a la que acometeremos aquí y, el segundo, sobre la Congregación de Plateros de San Eloy y las formas de ascenso de los plateros en ella. 
de nuestra provincia, la capital cuenta con algunos trabajos en la década de los ochenta mencionando especialmente a Villas Tinoco ${ }^{5}$, aunque también a Ruiz Povedano ${ }^{6}$, Quintana Toret y Pereiro Barbero ${ }^{7}$, a los que se suman Reder Gadow sobre los regidores Pizarro ${ }^{8}$ o Ybáñez Worboys acerca de grupos oligárquicos como los alcaldes mayores u otros con menor entidad como los escribanos ${ }^{9}$.

Estos importantes estudios contrastaban con un vacío bibliográfico de cara al resto de la provincia, salvado gracias a las aportaciones de Pezzi Cristóbal para el municipio veleño, estudiándolo desde el punto de vista político-administrativo, económico y social ${ }^{10}$. No obstante, municipios de relevancia histórica como Ronda, Marbella o Antequera no han sido aún objeto de estudios de calado en cuanto a su órgano rector.

Por su parte, y siguiendo un orden ascendente, la historiografía española ha visto crecer de manera exponencial la producción interesada sobre las élites urbanas en los últimos tiempos. Hace algo menos de veinte años, Soria Mesa realizó un balance sobre los estudios al respecto, destacando que pese a este marcado desarrollo, todavía quedaba bastante por hacer ${ }^{11}$.

Efectivamente, el panorama actual difiere sobremanera del que expuso el historiador. Entre otros territorios, el norte peninsular se caracterizaba, según este, por una desoladora ausencia de análisis sobre los sectores sociales que aglutinaron el poder municipal. Hoy día, la labor realizada por las historiadoras Faya Díaz para Asturias ${ }^{12}$ o por López Díaz para el reino de Galicia ${ }^{13}$, entre otros, muestran todo lo contrario: la oligarquía norteña y, por consiguiente, su nobleza ha sido y es protagonista del interés de los investigadores.

Por lo tanto, se cuenta en la actualidad con un alto número de investigaciones, a nivel regional, de gran utilidad para establecer comparativas entre los sectores sociales que conformaron los cabildos, sin que estas

5. S. Villas Tinoco (1979); S. Villas Tinoco (1996).

6. J. M. Ruíz Povedano (1989).

7. F. J. Quintana Toret y P. Pereiro Barbero (1986).

8. M. Reder Gadow (1997).

9. P. Ybáñez Worboys (2002); P. Ybáñez Worboys (2004)

10. P. Pezzi Cristóbal (2003a); P. Pezzi Cristóbal (1995); P. Pezzi Cristóbal (2003b); P. Pezzi Cristóbal (2006); P. Pezzi Cristóbal (2017).

11. E. Soria Mesa (2000), 186.

12. M. A. Faya díaz (2004); M. A. Faya díaz y L. Anes Fernández (2007); M. A. Faya DíAz (2014).

13. M. López Díaz (1993); M. López Díaz (2016). 
obras más recientes nos hagan olvidarnos de otras de gran calado como la publicada por Hernández Benítez en 1995 sobre el poder local de Madrid entre los siglos XVII e inicios del XIX ${ }^{14}$ o la de Tomás y Valiente en 1975 acerca de la venta de los regimientos en la ciudad de Salamanca ${ }^{15}$.

Otro de los elementos destacados por Soria Mesa en el artículo anteriormente mencionado es el descuido por parte de los investigadores con respecto a las familias de los oligarcas estudiados, haciendo hincapié en la relevancia de la genealogía como fuente histórica ${ }^{16}$. Esta disciplina, prolífica durante la Edad Moderna como él mismo ha atestiguado, fue básica para la creación de argumentarios destinados al ascenso social, por lo que escudriñar y analizar las líneas genealógicas de los linajes sería vital para la comprensión de sus raíces y en qué dirección se utilizaron ${ }^{17}$.

Sin embargo, bajo mi punto de vista, Soria Mesa olvida mencionar la importancia de la historia de la familia y su metodología de acercamiento para solventar este escollo. Dicha rama histórica tuvo un gran auge a finales del siglo XX e inicios del presente con significativas aportaciones llegadas primero desde la universidad de Santiago de Compostela, por parte de Eiras Roel, o desde la universidad de Murcia, con Chacón Jiménez a la cabeza.

De hecho, ha sido la historia de la familia la que ha propiciado una diferenciación terminológica entre los conceptos linaje, casa y familia; básico para el estudio no sólo, aunque sí en una parte importante, de los grupos oligárquicos y nobiliarios, por las aportaciones de Hernández Franco $^{18}$. Todas estas contribuciones, que no podemos exponer aquí, se han visto sintetizadas en una obra de referencia publicada hace escasos años, en 2011, y en la cual, también con la colaboración de Hernández, se ha expuesto la transcendencia de la sangre como instrumento socioinstitucional ${ }^{19}$.

La tercera de las deficiencias planteadas por Soria Mesa viene producida por la propia definición del concepto oligarquía, pues expone que

14. M. Hernández Benítez (1995).

15. F. Tomás y Valiente (1975).

16. E. Soria Mesa (2000), 191.

17. E. Soria Mesa (2004).

18. Vide la publicación realizada al calor del Congreso Internacional de Historia de la Familia celebrado en Murcia en 1994. J. Casey y H. Hernández Franco (1997). Además, otras aportaciones de gran calado en cuanto a la distinción de conceptos como familia, casa y hogar. F. CHACón Jiménez (2007)

19. J. Hernández Franco (2011). 
"el propio objeto de estudio es un elemento que no se suele definir, o al menos no con la necesaria exactitud" ${ }^{20}$. Posteriormente pasa a afirmar que la oligarquía en sí misma no es nobleza. La aseveración es, cuanto menos, de gran interés y viene a transmitir la propia imprecisión del concepto que barajamos $^{21}$.

A lo primero que nos remitimos es a las dos definiciones ofrecidas, la primera por el Diccionario de Autoridades donde se dice que es el "Gobierno de pocos, y es cuando algunos poderosos se aúnan, para que todas las cosas dependan de su arbitrio, que es el vicio que suele degenerar la aristocracia"22. La segunda por el Diccionario de la Real Academia Española que, en su vigesimotercera edición, la define como la "forma de gobierno en la cual el poder político es ejercido por un grupo minoritario"23.

Es decir, ambas acepciones vienen a reafirmar el carácter minoritario como grupo de poder que es, sin especificar en ningún caso nobleza alguna. Por lo tanto, ciertamente, no podríamos hablar de una nobleza stricto sensu, aunque sí de unos comportamientos culturales que vienen a equipararse a los de la aristocracia, en sus modos de actuación y en sus comportamientos familiares.

Empero, el patriciado urbano no sólo emuló actuaciones determinadas, sino que con ello persiguió una mejora social dentro del común que lo llevará a escalar dentro del grupo privilegiado, hecho que veremos a continuación mediante la familia Gálvez ${ }^{24}$.

Nuestro trabajo se fundamenta en la documentación extraída del Archivo Histórico Nacional, procedente las secciones Hacienda, Inquisición y Estado, así como de los fondos de Protocolos Notariales, Judicial, Municipal y Archivos Familiares conservados en el Archivo Histórico Municipal de Antequera ${ }^{25}$.

20. E. Soria Mesa (2000), 189.

21. P. Pezzi Cristóbal (2006), 427-430.

22. Diccionario de Autoridades (1780), 664.

23. Diccionario de la Real Academia Española (2014)

24. Acerca de los espacios de actuación de la oligarquía, que marcan profundamente sus intereses vide M. López Díaz (2014).

25. La búsqueda documental en esta entidad no habría sido posible sin la inestimable ayuda de su archivero, José Escalante Jiménez. 


\section{DE OSUNA A ANTEQUERA: EL LAPSO ARTESANAL}

Como citamos anteriormente, ya otros de nuestros trabajos se han dirigido hacia el análisis de la proyección del linaje Gálvez, aunque enfocados a una línea familiar más vinculada con el sector artesanal, concretamente con la platería antequerana ${ }^{26}$. Va a ser dicha profesión la que comenzó a desarrollar en la ciudad el primer Gálvez tras su llegada desde Osuna en las décadas finales del siglo XVII, sin embargo, sería impreciso afirmar que las raíces del clan se encuentren en el desempeño de este oficio, pues desconocemos su pasado previo al establecimiento.

El primero de los miembros radicados en Antequera fue Francisco Miguel de Gálvez Bermudo, como nos descubre una limpieza de sangre solicitada por dos de sus hijos, Alonso y Francisco, que aporta luz a la raigambre del clan ${ }^{27}$. En ella, se nos dice que el mencionado Francisco Miguel fue hijo de Juan de Gálvez e Isabel Bermudo, siendo bautizado el 17 de abril de 1673 en la Iglesia Colegial de la villa de Osuna ${ }^{28}$. Asimismo Alonso, el segundo de sus vástagos, declara que:

Como a poco tiempo de haber nacido dicho mi padre se pasaron de esta villa [de Osuna] a la ciudad de Écija los dichos Don Juan de Gálvez y Doña Isabel Bermudo donde hicieron vida maridable y de donde eran naturales habiéndose dejado en esta villa a dicho mi padre y su crianza al cuidado de Doña María Juárez de Figueroa con quien tenían mucha amistad y la expectativa de que le dejaría gran parte de su caudal por no tener hijos la referida, como sucedió con efecto a su testamento que hizo la dicha Doña María Juárez ${ }^{29}$.

Unos cuidados que duraron aproximadamente ocho o nueve años, dejándole tras su muerte un número considerable de posesiones por ser "rica y sin tener heredero forzoso", según aseguró uno de los testigos incluidos en el auto.

26. F. Hidalgo Fernández (2019).

27. Soria Mesa pone de manifiesto la cotidianeidad del uso de la genealogía durante la Edad Moderna, donde el conocimiento del pasado familiar fue clave para el posicionamiento dentro de la sociedad, por lo que las limpiezas de sangre, las genealogías o las pruebas de hidalguía estuvieron a la orden del día para cualquier aspecto, máxime si se optaba a una cierta preponderancia entre el común. E. Soria Mesa (2004), 29-35.

28. Bautizado el 17 de abril de 1673. Archivo Histórico Municipal de Antequera (AHMA), Protocolos Notariales, escribanía de Bernardo José de Lasarte, leg. 262, fol. 167r. Limpieza de sangre de Alonso y Francisco Gálvez de Almoguera, 1725.

29. Ibidem, fol. 169v. 
Después pasaría con corta edad a la ciudad de Antequera, aunque no conocemos ni la fecha ni las circunstancias o redes sociales existentes para este desplazamiento ${ }^{30}$. Obviando, por tanto, estas etapas originarias, el que fuera iniciador de estos Gálvez en la ciudad ${ }^{31}$, contrajo matrimonio con María Francisca Almoguera y Rojas del cual nacieron Francisco y Alonso Gálvez de Almoguera.

Con respecto al primero de los Gálvez, Francisco Miguel, destacar tan sólo dos cuestiones. La primera sobre su ocupación profesional, supuestamente vinculada con la platería antequerana. Sánchez-Lafuente lo menciona haciendo referencia a una naveta ubicada en la iglesia de Santiago adjudicándole, por consiguiente, la marca personal GAL/BES ${ }^{32}$. Dicha pieza va a estar, sin embargo, fechada en 1743, tres años después de la muerte del pretendido platero $^{33}$. Teniendo en cuenta la herencia a la que hicimos referencia anteriormente, el nivel económico le pudo permitir la administración de un taller en propiedad en el cuál no ejerciera como trabajador, hecho que se une, asimismo, con el rechazo de la nobleza, aunque fuera baja, a las labores manuales ${ }^{34}$. Esta ocupación, sin embargo, fue seguida por Alonso que aparece en el Catastro de Ensenada de 1753 como maestro platero ${ }^{35}$.

La segunda, y última, de las apreciaciones enlaza precisamente con este carácter de baja nobleza, base para la progresión social de las posteriores generaciones a lo largo de los siglos XVIII y XIX. Sin ser nuestro objetivo dilucidar cuáles fueron los orígenes, ciertos o no, de la nobleza de sangre de los Gálvez en la ciudad de Écija, ya en Antequera estos quedaron adscritos al estamento por lo menos desde 1706, gracias al padrón elaborado al calor de la contienda sucesoria que por aquel momento vivía el trono hispánico.

30. Ibidem, fols. 170r-173v.

31. Existe en Antequera, además de este linaje, otra familia con el apellido Gálvez, posicionada en la ciudad desde momentos anteriores, sin encontrar ninguna relación entre ambas.

32. R. Sánchez-Lafuente Gemar (1997), 324.

33. AHMA, Fondo Parroquial, Parroquia de San Sebastián, lib. 514, fol. 185r. Defunción de Francisco Miguel de Gálvez Bermudo, 24 de agosto de 1740.

34. Como apunta Pérez León, la sociedad del Antiguo Régimen se caracterizó por un deseo en cuanto a la obtención de signos de distinción, por lo que en muchos casos las formas de conseguirlos fueron mediante la manipulación de probanzas como la que hemos destacado. Por lo que las afirmaciones en ella contenidas han de ser tomadas desde el análisis crítico, máxime si estas no están refrendadas por otros documentos. J. Pérez León (2010), 123-124.

35. AHMA, Catastro de Ensenada, Lb. 1997, fols. 404r-405v. Alonso de Gálvez, 1753. 
En 1706, ante las dificultades que el bando borbónico estaba atravesando frente al avance austracista, se produjo un llamamiento a la nobleza con el fin de que estos prestaran ayuda al monarca legítimo bajo las órdenes del marqués de Villadarias. Este llamamiento se dirigió desde el primer momento, aunque no fuera de forma explícita, al estrato medio-bajo aristocrático ${ }^{36}$, pasándose, a continuación, a la inscripción de estos en un padrón, no conservado en el caso de Antequera.

Como bien señalan Gutiérrez Nieto e Ybáñez Worboys, el conflicto se va a convertir en un escenario propicio para satisfacer las pretensiones de promoción social de muchos individuos, pues gracias a los servicios prestados a la Corona podrían involucrarse entre los sectores hidalgos para desde ahí escalar a otras posiciones más elevadas ${ }^{37}$. De hecho, y aunque hemos señalado que el padrón antequerano no se conserva en la actualidad, podemos conocer la inscripción de Francisco Miguel de Gálvez Bermudo en el mismo gracias a documentación indirecta: "Don Francisco Miguel de Gálvez, pronto con sus armas y caballo"38.

No conocemos más referencias acerca del referido padrón, exceptuando que José Salvador de Almoguera también estaba inserto ${ }^{39}$, pero podemos suponer que ante la difícil situación que vivieron las tropas de Felipe V, Antequera respondió como en años anteriores, 1702-1704: en palabras de Ruiz Ortega los voluntarios antequeranos “cuando de defender la Patria se trata, nada escatiman"40.

\section{ENLACES MATRIMONIALES Y PRIMEROS PASOS EN EL CABILDO MUNICIPAL}

Tal y como testimonió durante el siglo XVII García de Yegros, “también ennoblece a esta Ciudad la gente principal de su población, que tan más estimada es y noble la República, cuando gentes nobles la habitan; como lo está Antequera de muchos caballeros hidalgos, gente principal, de conocida nobleza y virtud" ${ }^{41}$. Tras observar el posible camino de inicio de la aristo-

36. F. J. Gutiérrez Nieto y P. Ybáñez Worboys (2007), 53-62.

37. Ibidem, 67.

38. Archivo Histórico Nacional (AHN), Estado-Carlos III, Exp. 1487, fol. 32r. Pruebas de nobleza don Francisco de Gálvez Velasco, nombrado caballero de la Real y Distinguida Orden de Carlos III, 1815.

39. José Salvador de Almoguera, suegro de Francisco Miguel de Gálvez Bermudo, fue padre junto con María de Rojas y Ortega de María Francisca de Almoguera y Rojas.

40. J. Ruiz Ortega (1955), 216-217.

41. A. García de Yegros (1915), 35. Destacamos aquí el caso de Vélez-Málaga donde 
cratización familiar, pasamos a resaltar a dos de sus miembros: Francisco de Gálvez Almoguera y su hijo Antonio de Gálvez Montoya; observando en ellos los primeros pasos dados dentro del Cabildo, así como la creación de unas estrategias matrimoniales bien zurcidas y de excelentes resultados.

\subsection{El primer puesto municipal: Francisco de Gálvez, alcalde ordinario}

La introducción de los Gálvez entre la hidalguía antequerana va a suponer un verdadero acicate en cuanto a la proyección del linaje, pues si el segundo vástago se dedicó al oficio platero, el primogénito, Francisco de Gálvez Almoguera, inició una línea familiar donde las estrategias matrimoniales, el beneficioso panorama económico y la introducción en el Cabildo fueron trascendentales para su integración en la oligarquía local.

Una de las diferencias principales existentes entre el primogénito y su hermano va a ser la formación universitaria que el primero recibió, ya que, a través de la limpieza de sangre podemos conocer que Francisco de Gálvez se formó en medicina en la Universidad de Osuna ${ }^{42}$.

No es nuestro fin exponer aquí el panorama de la universidad hispánica durante la Edad Moderna, sino apuntar brevemente que, frente a una etapa áurea en el siglo XVI, la institución entró en receso en las dos centurias posteriores ejemplificándose en un descenso en las matrículas de estudiantes, algo que manifiesta un retroceso en cuanto a la confianza de las capas altas y medias de la sociedad hacia la formación ofrecida en estas entidades académicas ${ }^{43}$. Pese a todo, no debemos olvidar que la Universidad fue no sólo un espacio formativo sino también un instrumento de ascenso social, y como tal debemos entender la instrucción que Francisco de Gálvez recibió en la villa de Osuna, a la vez que se muestra como indicativo del capital familiar disponible para hacer frente al coste de matrícula y a la manutención ante la lejanía del hogar ${ }^{44}$, aunque, bien es cierto que la vinculación del clan con Osuna era larga, por lo que la existencia de contactos en esta

también se ensalza a la ciudad mediante el abolengo de sus habitantes. P. Pezzi CrisTÓBAL (2006), 431.

42. AHMA, Protocolos Notariales, escribanía de Bernardo José de Lasarte, leg. 262, fol. 180v. Limpieza de sangre de Alonso y Francisco Gálvez de Almoguera, 1725.

43. Sobre la evolución de la universidad hispánica véase R. KAGAN (1981); A. Álvarez de Morales (1985); L. E. Rodríguez-San Pedro Bezares (2002); J. M. Imízcoz Beunza y A. Chaparro Sainz (2013).

44. Los estudios de medicina en la universidad de Salamanca suponían alrededor de unos 9.000 reales. M. SÁnchez-Granjel Santender (2009), 321; Sánchez García (2014), 8. 
villa favoreció la elección del centro universitario, frente a otros como el de Granada, y la permanencia del estudiante durante la etapa académica.

Escasos conocimientos tenemos acerca del desempeño de su oficio de galeno, tan sólo las intitulaciones dadas en los distintos documentos notariales familiares, así como un sermón publicado en torno a 1731, donde se dice fue "Médico de Honor con ejercicio de la Real Casa, y familia de Su Majestad”45. Una carrera que si por algo se caracterizó fue por la nula movilidad hacia otras poblaciones, hecho harto frecuente entre los facultativos de la época, quizás por la buena hacienda familiar, por el beneficio obtenido en la ciudad o por las relaciones que se fraguaron en ella ${ }^{46}$.

Pero, si común fue durante los tiempos modernos la movilidad de los médicos también lo fue su economía solvente y el apoyo recibido por parte de los munícipes, debido a la importancia de su actividad ante posibles episodios epidémicos. Este hecho explica el nombramiento de Francisco como alcalde ordinario en 1732, aunque no se haya encontrado noticia alguna del desempeño del cargo en el libro capitular pertinente ${ }^{47}$ :

El señor don Juan Pardo regidor a quien tocó en suerte un alcalde ordinario, nombró en él a Don Francisco de Gálvez y Almoguera, médico honorario de la Real Familia y la ciudad tuvo por nombrado por concurrir en su persona las calidades necesarias para ostentar este empleo ${ }^{48}$.

Pero para comprender completamente la trayectoria vital de Francisco de Gálvez debemos hacer mención a su unión nupcial, pues su primera y única esposa trajo consigo importantes elementos que nos llevan a definirlo como uno de los desposorios más relevantes para la familia de toda la centuria. El matrimonio entre Francisco de Gálvez y Juana Montoya aconteció el 4 de septiembre de 1721 iniciándose una convivencia que perduraría hasta la muerte del marido en $1734^{49}$.

45. J. Vivas de Montoya y Bexines (1731).

46. M. Sánchez-Granjel Santender (2009), 321-322.

47. No consideramos una anomalía la ausencia de referencias en las actas municipales, sino todo lo contrario pues fue un hecho frecuente debido a la condición misma del cargo.

48. AHMA, Fondo Municipal, lib. 1726, s. f. Nombramiento de Francisco de Gálvez Almoguera, 1732.

49. AHMA, Fondo Parroquial, lib. 514, fol. 185r. Matrimonio de Francisco de Gálvez y Juana Montoya, 4 de septiembre de 1721. 
Nacida en una fecha imprecisa entre finales del siglo XVII e inicios del XVIII, Juana Montoya fue hija de Roque Montoya, jurado del Ayuntamiento antequerano, y Andrea Dionisia de San Buenaventura Aguilar y Torres Muñoz de Estepa. Se producía así el enlace entre el clan Gálvez y los apellidos Aguilar y Muñoz de Estepa, saga familiar que, aunque oriunda de Estepa, tuvo gran repercusión en la historia de Antequera hasta el siglo XIX ${ }^{50}$.

Juana ya había contraído nupcias anteriormente con Juan Tomás de Lara Casasola en agosto de $1716^{51}$, de cuyo matrimonio nació María Josefa Lara y Montoya. Viuda ya en 1721, se configuraba como un excelente partido ante unas segundas nupcias pues no sólo administraba la herencia de su hija, sino que también era beneficiaria de los bienes de otros familiares cercanos. Con todo ello, se desposaba ese mismo año con el médico Francisco de Gálvez ${ }^{52}$.

Como decimos, el cariz que, sin duda, da verdadera enjundia al enlace es la posesión por parte de Juana de un vínculo creado en 1714 por Francisca Aguilar, su tía materna, que le daba una acomodada posición económica y sentaba las bases para el ansiado ascenso social.

Los orígenes de la familia de Francisca Aguilar son desconocidos, debido a la inexistencia de estudios que ahonden en las raíces de un apellido tan conocido en Antequera. Podemos decir, sin embargo, amparándonos en la primera dote de la tía de Juana, que la situación hacendística no fue boyante, por lo menos a finales del seiscientos. Su primer matrimonio se produjo con Juan Arroyo Crespo, en $1699^{53}$, ofreciendo la esposa una cuantía al himeneo de apenas 5.885 reales $^{54}$. En 1703, el marido moría

50. Nos remitimos a un árbol genealógico de los Muñoz de Estepa incluido en el Archivo de la familia Aguilar, aunque este incluye tan sólo miembros del linaje del siglo XVII. AHMA, Archivo Aguilar, C. 45, carp. 23, Árbol Genealógico de los Muñoz de Estepa. Vide, además, el estudio sobre élites locales durante el siglo XIX de A. PAREJo BARRANCO (1998).

51. AHMA, Fondo Parroquial, lib. 514, fol. 22r. Matrimonio de Juan de Lara y Juana Montoya, 9 de agosto de 1716.

52. Juana Montoya no acató el plazo establecido entre la muerte de un marido y las segundas nupcias. M. BirRiel SAlcedo (2008). Además, ejemplifica la asiduidad de los nuevos desposorios entre las viudas de la Edad Moderna, pese a las palabras de los moralistas del momento. Vide A. Nausia Pomoulier (1998) y I. Rodríguez Alemán (2008).

53. AHMA, Fondo Parroquial, lib. 512, fol. 292r. Matrimonio de Juan de Arroyo Crespo y Francisca de Aguilar, 06 de abril de 1699.

54. La cantidad ofrecida queda muy por debajo de la proporcionada incluso por sectores artesanales como los plateros, cuyas cantidades rondarían los 20.000 reales. A. M. Moral Roncal (1998), 422-425. 
sin haber tenido aún descendencia, dejando a su esposa como única y universal heredera, por lo que además del reembolso de la dote, Francisca veía aumentada su hacienda personal de forma considerable, quedando en su posesión una serie de bienes que ascendieron, cuanto menos, a 73.075 reales de vellón, destacando de ellos un número considerable de ganado y de fanegas de trigo y cebada ${ }^{55}$.

Viuda, Francisca Aguilar se desposó de nuevas con Cristóbal García Salvadores, aunque como ocurrió en su primer matrimonio el cónyuge feneció pronto, en septiembre de 1713 sin dejar descendencia alguna, quedando la mujer, de nuevo, como única y universal heredera. Sin embargo, acabó repudiando dichos bienes en unas circunstancias que expuso la misma Francisca en su testamento:

Me instituyó asimismo por su única heredera y habiendo muerto, ante la justicia de esta dicha ciudad que por ante dicho presente secretario y escribano acepté la herencia con beneficio de inventario que habiéndose hecho y pasado a otras diligencias que del curso de la dependencia resultaron por haber ocurrido muchos acreedores pretendiendo satisfacción de crecidas cantidades que dicho mi segundo marido les debía y hallándome yo la otorgante primera acreedora por mi dote y arras y pretendiendo otras acciones repudié dicha herencia la cual don Juan del Campo Tejada primo hermano de dicho mi marido y su legatario por el derecho de sangre y como pariente más cercano salió aceptando dicha herencia con el mismo beneficio y habiendo precedido a precios y otros muchos autos y yo la otorgante ejecutado por mi dote y arras y hecho intento sobre ciertos agravios que deduje y ofrecí, justifican habiéndose vinculado lo uno y otro con el dicho don Juan del Campo y con los acreedores todos los unos y otros nos convenimos en que se procediese a las cuentas, pagos y adjudicaciones haciéndome a mi la otorgante primeramente pago de dicha mi dote y arras y de seis mil seiscientos y tantos reales en que convenimos los agravios de dicha mi pretensión [...] y faltaron por entregarme diez y siete mil y tanto reales y respecto de que yo la otorgante he de ser pagada de ellos en especie de dinero ${ }^{56}$.

55. Debemos mencionar, además, que Juan de Arroyo había contraído anteriormente nupcias, sin dejar tampoco descendencia. AHMA, escribanía de Juan Luque Tisón, leg. 1066, fols. 288r-291v. Capital otorgado por Juan de Arroyo Crespo, 4 de marzo de 1700. AHMA, escribanía de Juan Luque Tisón, leg. 620, fols. 322r-324v. Testamento otorgado por Juan de Arroyo Crespo, 7 de octubre de 1703. AHMA, Fondo Parroquial, lib. 545, fol. 188r. Defunción de Juan de Arroyo Crespo, 12 de octubre 1703.

56. AHMA, escribanía de Francisco Montaño Serrano, leg. 1883, fols. 245r-245v. Testamento de Francisca de Aguilar, 28 de junio de 1714. Asimismo, cabe mencionar que lo narrado 
Con los bienes acrecentados durante su vida y la cantidad dotal devuelta, Francisca pasó a crear, mediante vía testamentaria ${ }^{57}$, un vínculo ya que:

Dejando los bienes libres y sueltos se consumen y acaban y las familias quedan sin el lustro que pueden tener de quedar conservados y unidos en vínculo con la prohibición de su enajenación mediante lo cual con sus rentas pueden pasar y pasan con toda decencia y más bien pueden cumplir el servicio de Dios nuestro señor y defensa de su santa fe católica y por consiguiente a los señores los reyes y defensa de su monarquía para que más bien y con mayor seguridad esté ensalzada nuestra eclesiástica fe; mi intención y voluntad ha sido y es de fundar como desde luego fundo vínculo de los bienes siguientes ${ }^{58}$.

Los bienes incluidos fueron, además de la dote proporcionada en su segundo matrimonio a la que ya hicimos referencia, una casa principal y una casa bodegón, ambas en calle Nueva y "una heredad de viña y olivar con su casa con molino de aceite, lagar y bodegas en el término de esta ciudad partido de la Isla de Biedma que se compone de diez y seis aranzadas" ${ }^{59}$.

Este vínculo recayó en la persona de Juana Montoya ${ }^{60}$, su sobrina, quien aparece en el Catastro de Ensenada como viuda y poseedora no sólo

en la escritura testamentaria no es más que el resultado de un proceso judicial con un mal estado de conservación. AHMA, Fondo Judicial, C. 60, carp. 13. Pleito de ejecución de Francia de Aguilar Muñoz de Estepa, viuda de Cristóbal García de Salvadores, contra los bienes y caudal de su marido por su dote y arras, 10 de abril de 1714 .

57. Aunque clásico, el estudio de Bartolomé Clavero acerca del mayorazgo desde el siglo XIV al XIX se conforma actualmente como el mejor acercamiento al tema de la propiedad feudal castellana. Vide capítulo noveno sobre la fundación de mayorazgos. B. Clavero Salvador (1974), 222-239.

58. AHMA, escribanía de Francisco Montaño Serrano, leg. 1883, fol. 247v. Testamento de Francisca de Aguilar, 28 de junio de 1714. Se pone de relieve en este fragmento como el mayorazgo supone no sólo un instrumento de riqueza material sino también inmaterial, pues tiene como uno de sus objetivos mantener viva la memoria del linaje y particularmente de su fundadora. M. Pérez García (2009), 1120.

59. AHMA, escribanía de Francisco Montaño Serrano, leg. 1883, fol. 247v. Testamento de Francisca de Aguilar, 28 de junio de 1714.

60. Como expone Clavero, la voluntad del fundador del mayorazgo prima en el proceso de creación y traspaso, estableciendo este el sistema transmisión de los bienes. En el caso de Francisca Aguilar, aunque nombra a su sobrina como primera heredera, dispone que el vínculo ha de recaer sobre el primogénito antes que el resto y sobre el varón antes que la mujer. AHMA, escribanía de Francisco Montaño Serrano, leg. 1883, fol. 247v. B. Clavero Salvador (1974), 232-233. Testamento de Francisca de Aguilar, 28 de junio de 1714 . 
de los bienes llegados por el legado de su tía, sino también de otras casas y cinco aranzadas más en el terreno de la Isla de Biedma ${ }^{61}$.

Dicha fundación fue base para el posicionamiento de Juana ante sus futuros matrimonios, favoreciendo su mejora social a través de hombres bien relacionados políticamente, aunque también ellos la vieron como un medio de incrementar la hacienda familiar ${ }^{62}$. Es con esta perspectiva bajo la que hay que analizar el matrimonio entre la referida y Francisco de Gálvez, pues este gozaría ya en la década de los 20 de una buena posición en la ciudad, y la dote ofrecida por Juana a este segundo desposorio, que ascendió a 44.419 reales y 31 maravedíes, fue acrecentada por Francisco de Gálvez en 400 ducados. Además, el nuevo esposo declaraba que renunciaba a las leyes de la entrega excepción non numerata pecunia pues se confesaba contento con la efectiva entrega de los bienes, entre los que destacamos un considerable número de arrobas de vino y vinagre, reflejo del beneficio extraído por las tierras del vínculo, y de un oficio de procurador tasado en 2.200 reales de vellón ${ }^{63}$.

Gracias a todo lo expuesto, los Gálvez comenzaban su andadura en el Cabildo antequerano, introduciéndose en un nuevo espacio de sociabilidad excelente en cuanto a la posibilidad de inserción en redes clientelares. Dos años más tarde, en 1734, Francisco moría bajo una disposición testamentaria otorgada ante el escribano Francisco de Talavera datada en 5 de mayo de $1730^{64}$.

\subsection{Antonio de Gálvez Montoya: escribano del número}

El matrimonio Gálvez Montoya trajo consigo tres hijos: el primogénito Antonio, nacido el 27 de octubre de 1722, ahijado de su tío paterno Alonso de Gálvez ${ }^{65}$; Francisca Ventura, aproximadamente alumbrada en 1729-1730; y, por último, Roque, el 24 de septiembre de 1732, cuyo padrino fue el

61. AHMA, Catastro de Ensenada, lib. 1989, fols. 1181r-1183v. Juana de Montoya.

62. A. Nausia Pimoulier (2006), 247-248.

63. AHMA, escribanía de Miguel Francisco de Talavera, leg. 2504, fols. 766r-780r. Escritura de dote de Juana Montoya contra Francisco de Gálvez, 22 de diciembre de 1721.

64. AHMA, Fondo Parroquial, lib. 548, fol. 200v. Defunción de Francisco de Gálvez Almoguera, 15 de julio de 1734. AHMA, Fondo Notarial, escribanía de Francisco de Talavera, leg. 2516, fols. 124r-129v. Testamento de Francisco de Gálvez Almoguera y Juana Montoya Aguilar, 5 de mayo de 1730.

65. Alonso de Gálvez fue un platero antequerano de mediados del siglo XVIII. F. Hidalgo FERNÁNDEZ (2019). 
mismo que el de su hermano mayor ${ }^{66}$. De ellos, nos centraremos, fruto de la línea marcada en este trabajo, en Antonio de Gálvez.

Bautizado bajo el nombre de Antonio Ignacio Florentino José, el primero de los hijos del médico y alcalde ordinario y la heredera del vínculo fundado por Francisca Aguilar, Juana Montoya, tuvo, en principio, al igual que su padre una formación universitaria en la villa de Osuna, aunque desconocemos qué rama del conocimiento cultivó. La primera diferencia observada viene dada en este plano, en cuanto a los posibles familiares disponibles ante la formación superior. Así, mientras su abuelo paterno mandó únicamente al primogénito a la universidad, en el caso de su padre también su hermano menor, Roque, tuvo una educación académica, en este caso medicina. De hecho, su madre hizo referencia a la estancia de ambos en dicha villa en su testamento como viuda, en los siguientes términos:

Declaro que dicho Don Antonio de Gálvez Montoya, mi hijo, empezó los estudios para facultad en la Universidad de Osuna en que hice diferentes gastos tanto para sostenerlo me estreché bastantemente, y lo mismo pasó con el dicho Don Roque que para costearle el grado de Bachiller fue necesario imponer sobre mis bienes un censo de cincuenta ducados, y por motivos justos que me asisten es mi voluntad soltarles como les suelto y remito estos gastos para que no se les cuenten ni carguen en manera alguna ${ }^{67}$.

La instrucción, completa o no, pues solo se indica que "empezó los estudios", era costosa, como ya mencionamos para el caso anterior, de ahí las estrecheces testimoniadas por su madre que, si bien liberó de cargas a sus dos vástagos varones, mejoró la herencia de su única hija mediante una serie de alhajas de oro, diamantes y esmeraldas ${ }^{68}$.

66. AHMA, Fondo Parroquial, lib. 440, fol. 180v. Partida de bautismo de Antonio de Gálvez Montoya, 31 de octubre de 1722. AHMA, Fondo Parroquial, lib. 442, fol. 307. Partida bautismal de Roque de Gálvez Montoya, 25 de septiembre de 1732. AHMA, escribanía de Miguel Francisco de Talavera, leg. 2516, fols. 124r-129v. Testamento de Francisco de Gálvez y Juana Montoya, 5 de mayo de 1730. Sobre el padrinazgo a lo largo de la Edad Moderna, vide G. Alfani y V. Gourdon (2016).

67. AHMA, escribanía de Esteban de Rojas Ballartas, leg. 183, fol. 74v. Testamento de Juana Montoya, 30 de julio de 1753.

68. AHMA, escribanía de Esteban de Rojas Ballartas, leg. 183, fols. 75r-75v. Testamento de Juana Montoya, 30 de julio de 1753. La vía de mejora se explica además por el hecho de ser una doncella menor, por lo que se dirigiría fundamentalmente al incremento de una futura dote. Asimismo, se pone de relieve como el mayorazgo o los vínculos no fueron un órgano inmóvil, sino que frente a un pretendido sistema hereditario marcado, este tuvo instrumentos como la vía de mejora. J. Díaz Álvarez (2004), 93. 
Pese a ello, Antonio nacía como primogénito y, por tanto, como heredero de un vínculo acrecentado por sus padres y en posesión de su madre tras quedar viuda en 1734 . Además, la introducción de su progenitor en el cabildo antequerano le abrió la puerta a toda una serie de relaciones clientelares y la posibilidad de llevar a cabo enlaces matrimoniales dirigidos a su fortalecimiento ${ }^{69}$, viniendo a ratificar la afirmación de Díaz Álvarez de que "el estudio de las élites conlleva el estudio de las redes sociales de poder"70.

En esta línea cabe precisar que, si Francisco de Gálvez fue alcalde ordinario del cabildo antequerano en 1731, el que fuera su futuro consuegro ostentó durante algunos años el cargo de escribano del Ayuntamiento ${ }^{71}$. Sin embargo, la muerte temprana del primero va a suponer que la trayectoria vital de Antonio de Gálvez esté emparejada en mayor medida con su suegro, gracias al cual ejerció como escribano público tras la cesión del mismo entre 1754 y $1777^{72}$.

Hablamos, por ende, de un miembro del clan que no va a estar de forma explícita integrado entre los grupos de poder del cabildo municipal. No obstante, los escribanos se configuraron como un estrato social intermedio caracterizado por una gran movilidad, emulando en muchas ocasiones unas actitudes aristocráticas en cuanto a sus estrategias matrimoniales ${ }^{73}$.

Tendremos, por consiguiente, que exponer algunos datos acerca de esta otra familia con la que emparentaron. Gerónimo Velasco García, nacido en 1697 en Ortigosa, fue hijo de Pedro Velasco y María García, él natural de la villa de Nieva y ella de Villa Nueva de los Cameros. Ya a inicios del XVIII, la limpieza de sangre, realizada por Francisco de Gálvez Almoguera y su hermano, nos informa que salió de su localidad de origen

69. El estudio de Moutoukias sobre las redes clientelares forjadas entre comerciantes y oligarcas locales en las colonias americanas es buen ejemplo de ello. Z. MoutoukiAs (2002). Vide también el estudio sobre sociabilidad y política local en la Galicia moderna, M. López Díaz (2014).

70. J. Díaz Álvarez (2004), 91.

71. Sobre los escribanos del cabildo veleño dieciochesco véase P. Pezzi CristóBAl (2003a), 106-116.

72. Véase J. Escalante Jiménez (2016), 161.

73. F. J. Aranda Pérez (1999), 131-138; B. García Guillén (2009), 654-658. Para el caso malagueño destacamos alguna bibliografía de gran interés para las escribanías, aunque sin adentrarse en la faceta sociológica: M. Reder Gadow (1982); P. J. Arroyal Espigares, M. T. Martín Palma y E. Cruces Blanco (1991); P. Ybáñez Worboys (2004). Destacamos, sin embargo, pese a que se lo consideraríamos como una investigación genealógica el estudio de los Talavera de Antequera de J. Escalante JimÉnEz (2016). 
con la intención de hacer fortuna y que "tuvo noticia la hicieron"74. Su llegada a Antequera se fraguó gracias al enlace con una natural, Francisca Ramos, ocurrido en la iglesia de San Sebastián en 1719, que perduró hasta la muerte de ella en $1739^{75}$.

La primera noticia acerca de la actividad de Gerónimo data de 1723, año en que compró una escribanía a Nicolás Mauricio de la Barrera, aunque el documento acreditativo no se ha podido localizar en el Archivo Histórico Municipal de Antequera. El oficio, que había sido creado en 1586 para Juan Muñoz Valdivia, estuvo en manos de Gerónimo hasta 1754, fecha en que pasó a manos de su yerno, Antonio de Gálvez, ya marido de Gregoria Velasco y Ramos ${ }^{76}$. Sin embargo en esos mismos años, 1723-1754, Gerónimo adquirió otra escribanía, esta vez a María Javiera Lebrón, viuda de Julián Francisco Castellanos, que había ejercido la escribanía desde 1712, por 15.000 reales de vellón ${ }^{77}$. Con todo ello, y recordando que poseyó también la escribanía del Ayuntamiento, el oriundo de Ortigosa aparece en el Catastro de Ensenada con unas rentas anuales de 4.400 reales $^{78}$, cifra escasa en consonancia con las propiedades existentes.

Según los datos que acabamos de exponer, su actividad como escribano acabó a mediados de la década de los 50 , posiblemente en el momento en que su yerno Antonio pasó a ser propietario de la escribanía. Por otra parte,

74. AHMA, escribanía de Francisco de Rojas, leg. 1612, fol. 94r-94v. Testamento de Gerónimo Velasco y García, 14 de diciembre de 1759. AHN, Estado-Carlos III, Exp. 1487, fol. 25v. Pruebas de nobleza don Francisco de Gálvez Velasco, nombrado caballero de la Real y Distinguida Orden de Carlos III, 1815. Mientras que Gregorio hizo esa fortuna en Antequera, su hermano Miguel la hizo en La Habana.

75. AHMA, Fondo Parroquial, lib. 514, fol. 125v. Partida matrimonial de Gerónimo de Velasco y García y Francisca Ramos, 30 de julio de 1719. AHMA, escribanía de Francisco de Rojas, leg. 1612, fol. 95r. Testamento de Gerónimo Velasco y García, 14 de diciembre de 1759. El matrimonio entre un forastero y una foránea fue harto común como un elemento estabilizador. J. Bravo Lozano (1992), 25.

76. J. Escalante JimÉnez (2016), 161; AHMA, Fondo Parroquial, lib. 516, fol. 141r. Partida matrimonial de Antonio de Gálvez Montoya y Gregoria Velasco y Ramos, 8 de junio de 1742.

77. AHMA, escribanía de Miguel Francisco de Talavera, leg. 2495, fols. 658r-666v. Compra de la escribanía de Julián Francisco Sánchez Castellanos por Gerónimo Velasco García, 24 de diciembre de 1739. Este oficio de escribano fue comprado por su anterior propietario gracias a la dote proporcionada por su mujer, hecho común que se expone en M. P. Esteves Santamaría (2000), 144-145.

78. De ellos, 1.100 obtenido por el salario de la escribanía del Ayuntamiento; 1.500 por la escribanía de rentas provinciales; y 1.800 por el despacho de ellas. AHMA, Catastro de Ensenada, lib. 1997, fol. 5r. Gerónimo Velasco García, 1753. 
es destacable también que, entre los hijos de Gerónimo con Francisca Ramos, uno de ellos, José Antonio, fuese escribano real y de la Renta del tabaco, presente también este en el catastro con una renta anual de 5.300 reales, aunque quedó fuera del reparto de la herencia tras morir sin descendencia antes que su progenitor, en septiembre de $1757^{79}$.

Retomando la figura de Antonio de Gálvez Montoya, este también estuvo presente en el documento catastral de la siguiente forma: "Don Antonio de Gálvez Montoya, escribano de los Reinos sin oficio, se compone su familia de su mujer, un hijo menor y dos hijas: utiliza quinientos y cincuenta reales de vellón al año"80. Va a ser un año después, en 1754, cuando asuma la escribanía dejada por su suegro, la cual mantuvo durante más de veinte años. Esta actitud pasiva refleja fehacientemente la expectativa de Antonio a la llegada de la vejez de su suegro, siendo consciente de que sobre él recaería el oficio del anciano.

Su testamento, otorgado en 1796 arroja luz al asunto. Tras la muerte de su suegro, el 8 de septiembre de 1764, Antonio, pese a renunciar a la herencia, tomó de ella dos oficios de escribanía, de los cuales no conocemos, vía documental, su trayectoria. Tan sólo sabemos que tras abandonar el oficio en 1777 este pasó a Juan García de los Reyes ${ }^{81}$.

En otro orden de cosas, la que fuera su madre, Juana Montoya, quedó como poseedora del vínculo fundado por su tía hasta 1753, momento en el que por muerte pasó a manos de su primogénito. Asimismo, durante los últimos años de vida de Antonio, es decir, ajeno ya al oficio de escribano, el beneficio obtenido para su manutención vino dado de los terrenos del vínculo, así como del arrendamiento de propiedades. En este sentido, se ha podido localizar el que posiblemente fuera el último documento en el que aparece como propietario, pues data de 1804, fecha en el que murió ${ }^{82}$. En dicho contrato, Antonio de Gálvez arrendaba a Antonio Frías Delgado y María de los Remedios Correa una casa principal, localizada en calle Nueva durante cuatro años, con un coste anual de 80 ducados $^{83}$.

79. AHMA, escribanía de Francisco de Rojas, leg. 1612, fol.95v. Testamento de Gerónimo Velasco y García, 14 de diciembre de 1759. AHMA, Catastro de Ensenada, lib. 1997, fol. 6r. José Antonio de Velasco, 1753.

80. AHMA, Catastro de Ensenada, lib. 1997, fol. 4v. Antonio de Gálvez Montoya, 1753.

81. J. Escalante Jiménez (2016), 161.

82. AHMA, Fondo Parroquial, lib. 553, fol. 168r. Partida de defunción de Antonio de Gálvez Montoya, 12 de octubre de 1804.

83. Esta propiedad formó parte desde el comienzo del vínculo fundado por Francisca de Aguilar. AHMA, escribanía de Joaquín González Salgado, leg. 2420, fols. 65r.-66v. 
Como se ha podido observar, la muerte del que fuera alcalde ordinario, Francisco Gálvez de Almoguera, no supone un freno en cuanto a las posibilidades existentes de matrimonio, pues el factor verdaderamente clave fue, sin duda, la posesión de un mayorazgo, visto como un elemento no solo de ascenso económico-social, sino mayormente como un instrumento de asentamiento de una familia, la de los Velasco, que tan sólo llevaba una generación en la ciudad de Antequera.

Así, el matrimonio entre Antonio de Gálvez y Gregoria Velasco dejará tras de sí una numerosa progenie de siete hijos, más los difuntos en edad pupilar. Va a ser precisamente esta generación la que alcance la cota más alta no sólo dentro del cabildo municipal, sino también entre el sector eclesiástico y militar, logrando con ello un ascenso en cuanto a su nobleza ${ }^{84}$.

\section{UNA OLIGARQUÍA ASENTADA: LA GENERACIÓN GÁLVEZ VELASCO}

Hasta ahora hemos podido comprobar como desde la llegada a la ciudad, los Gálvez fueron posicionándose en un espacio cada vez más central de la sociedad antequerana donde la excelente estrategia zurcida durante dos generaciones llevó a la conversión de un clan, en principio, proveniente del mundo artesanal, aunque elevado, a su integración en los grupos de poder municipal. Sin embargo, la cúspide aún no había sido alcanzada y el puesto de regidor era, al fin y al cabo, una de las metas políticas más apreciadas.

Como hemos mencionado, el matrimonio entre Antonio de Gálvez y Gregoria Velasco dejó una numerosa descendencia por lo que debemos precisar que no atenderemos las trayectorias vitales de todos, sino tan sólo de dos que, a nuestro parecer, resultan de especial interés: Francisco Javier de Gálvez Velasco y Agustín de Gálvez Velasco. Ninguno de los dos fue el heredero del vínculo del que hemos venido haciendo referencia durante este trabajo, sino que este recayó sobre otro de los hijos, Antonio de Gálvez Velasco, cuya herencia fue, además, mejorada por su padre fruto del

Arrendamiento de Antonio Gálvez Montoya a Antonio Frías Delgado, 18 de febrero de 1804. I. González Sánchez (2004), 213.

84. Es imprescindible destacar en este punto el estudio de los Piédrola, radicados en VélezMálaga durante el siglo XVIII, pues responde a una trayectoria similar a la expuesta. P. Pezzi Cristóbal (2017). 
"mucho cariño y voluntad que profeso" y por "lo que se ha esmerado en contribuir al bien general de mi casa" ${ }^{85}$.

De hecho, poco más conocemos acerca del que fuera el principal heredero $^{86}$, tan sólo su dedicación como Guardia de Corps, al igual que casi la totalidad de sus hermanos. Suponemos, además, que tras su retirada del cuerpo ejerció algún tipo de oficio administrativo relacionado con la contaduría general de rentas en la ciudad de Antequera ${ }^{87}$, por lo que seguiríamos ubicándolo en la referida ciudad pese a que no hemos podido localizar ningún rastro documental sobre él, ni sobre si existió o no descendencia por su parte ${ }^{88}$.

A lo largo del presente artículo ha sido utilizada con bastante frecuencia la información ofrecida por las pruebas de nobleza de Francisco de Gálvez Velasco. Nacido el 3 de abril de 1761 fue el cuarto hijo del matrimonio. Tras décadas sin noticias sobre una hipotética formación académica, las únicas que nos llevan hacia su persona datan de 1815, es decir, cuando rondaba ya los 54-55 años.

Pese a que su padre se refirió a él como Guardia de Corps en su testamento de 1796, Francisco sobresalió frente a sus hermanos por los méritos obtenidos en su carrera eclesiástica. Así, en una prueba de sangre realizada por el Tribunal de la Inquisición de Granada se expone que fue presbítero canónigo con dignidad de tesorero de la iglesia Metropolitana de Granada, a la vez que estas averiguaciones iban dirigidas a su nombramiento como inquisidor honorario del Santo Oficio, como finalmente ocurrió ${ }^{89}$.

85. AHMA, escribanía de Antonio María de Talavera, leg. 2517, fol. 314v. Testamento de Antonio de Gálvez Montoya, 9 de julio de 1796.

86. En realidad, el primogénito fue José María de Gálvez Velasco (1756), sin embargo, el vínculo recayó en Antonio (1759) puesto que el primero murió en 1786 en Zaragoza, siendo teniente de capitán del regimiento de Flandes de Infantería. AHMA, escribanía de Antonio María de Talavera, leg. 2517, fol. 312v. Testamento de Antonio de Gálvez Montoya, 9 de julio de 1796.

87. Tan solo conocemos una misiva fechada en 9 de agosto de 1810 enviada a Gerónimo de Torres y Moya, contador general interino de la provincia de Málaga, sobre asuntos correspondientes a la Administración y Tesorería. AHN, Estado, C. 3068, fol. 283-285. Carta de Antonio de Gálvez Velasco a Gerónimo de Torres y Moya, 9 de agosto de 1810.

88. He de mencionar que el último rastro constatado se ubica en el testamento de uno de sus hermanos, Felipe de Gálvez, que lo nombra como uno de sus albaceas testamentario en 1824. AHMA, escribanía de Antonio María Cortés y Sánchez, leg. 2135, fols. 246r-247v. Testamento de Felipe de Gálvez Velasco, 25 de diciembre de 1824.

89. AHN, Inquisición, C. 1452, Exp. 22, s. f. Pruebas genealógicas de Francisco de Gálvez Velasco, 1815. 
Del mismo documento consideramos oportuno destacar el testimonio de Francisco Martín, cura de la iglesia antequerana de San Pedro, ya que expone el posicionamiento no sólo de Francisco, sino también del resto de sus hermanos.

Sabe que don Antonio de Gálvez y Montoya e hijos fueron inclusos en el padrón de nobleza que ejecutó esta ciudad en el año de mil setecientos setenta y cuatro y que don Antonio de Gálvez y Velasco es capitán de caballería retirado sirviendo antes en la clase de cadete garçon, como así mismo don Felipe, hermano del pretendiente, es teniente de caballería retirado sirviendo antes igualmente en el indicado cuerpo de Reales Guardias de Corps, como también don Agustín de Gálvez y Velasco es regidor perpetuo de esta ilustre ciudad, que el citado don Francisco de Gálvez es actual canónigo dignidad de tesorero de la Santa Iglesia de Granada, gobernador del mismo arzobispado sede vacante y caballero de la Real y Distinguida Orden de Carlos Tercero, y que otro hermano fue capitán en el Regimiento de Flandes ${ }^{90}$.

Como se puede observar, todos los hermanos alcanzaron puestos de consideración no sólo entre la guardia real sino también como regidor en el caso de Agustín, al que a continuación haré mención. Otro de los elementos a destacar va a ser su nombramiento como caballero de la Orden de Carlos III, pues es sabido también que no fue el único miembro del linaje que llegó a serlo.

Según expone Faya Díaz, entre las personas que obtuvieron un hábito de caballero se encontraron los cargos públicos $\mathrm{y}$, en definitiva, aquellos individuos que desempeñaron tareas en el gobierno del reino, su administración o en el servicio militar ${ }^{91}$. Suponía, por lo tanto, el reconocimiento a labores en pro del Estado, en unos momentos de inicios del siglo XIX donde el otorgamiento de este tipo de gracias aumentó de forma considerable si se compara con las ofrecidas durante los dos reinados anteriores ${ }^{92}$.

90. Ibidem.

91. M. A. Faya Díaz y L. Anes Fernández (2007), 23. Un caso concreto sobre la dedicación de los nombramientos puede verse entre los caballeros valencianos, P. Molas i Ribalta (1999).

92. La media anual de cruces otorgadas durante el reinado de Fernando VII fue 97,4, mientras que durante el reinado de su padre solo 58,9 y durante el de su abuelo y fundador Carlos III 29,5, siendo Andalucía a inicios de la invasión napoleónica la región con mayor número de condecoraciones, 248. A. De Ceballos-Escalera y Gila (2016), 105-208; P. Molas i Ribalta (1996), 61. 
Esta condecoración dejaba tras de sí la elaboración de una averiguación nobiliaria, conservada hoy en el Archivo Histórico Nacional. Para el caso de Francisco de Gálvez, fue aprobada en 5 de agosto de 1815, antes de ser nombrado como miembro del consejo de la Inquisición granadina, y llevada a cabo gracias a un decreto de 15 de octubre del año anterior ${ }^{93}$. Una trayectoria vital muy interesante que no podemos analizar aquí en profundidad.

Nos centraremos para finalizar en el hermano menor de los Gálvez Velasco, Agustín ${ }^{94}$. El que fuera a finales del XVIII visitador del resguardo real ${ }^{95}$, llegó en la centuria posterior a ser regidor perpetuo y alguacil mayor de Antequera ubicándose así en el gran peldaño de la política local, que funcionó al mismo tiempo como trampolín hacia la nacional, además de garantizar toda una serie de privilegios tanto protocolarios como económicos ${ }^{96}$.

La vida política de Agustín, que casó en mayo de 1794 con María de los Dolores Fernández del Pino ${ }^{97}$, se redujo al simple título de regidor, pues las ausencias en los libros de actas capitulares nos hablan de una total despreocupación por los acontecimientos municipales. La regiduría fue utilizada, por ende, como un instrumento de prestigio social y político, manifestando una evidente dejadez en cuanto sus funciones ${ }^{98}$.

La importancia de Agustín no radica, por tanto, en su actuación como munícipe, ni tampoco en una posición más elevada entre sus consanguíneos. La relevancia recae en el hecho de ser el primer miembro del clan

93. AHN, Estado-Carlos III, Exp. 1487, s. f. Pruebas de nobleza don Francisco de Gálvez Velasco, nombrado caballero de la Real y Distinguida Orden de Carlos III, 1815.

94. AHMA, Fondo Parroquial, lib. 451, fol. 52r. Partida bautismal de Agustín de Gálvez Velasco, 27 de octubre de 1765.

95. AHMA, escribanía de Antonio María de Talavera, leg. 2517, fol. 312v. Testamento de Antonio de Gálvez Montoya, 9 de julio de 1796.

96. Los distintos privilegios derivados de la posición política del regidor quedan detallados en el estudio sobre el poder municipal toledano de F. J. Aranda Pérez (1999), 88-90.

97. María Dolores Fernández del Pino fue a su vez viuda de primeras nupcias de José Sánchez Velasco. AHMA, Fondo Parroquial, lib. 522, fol. 70v. Partida matrimonial de Agustín de Gálvez Velasco y María de los Dolores Fernández del Pino, 25 de mayo de 1794.

98. M. López Díaz (2013), 145-150. No podemos conocer tampoco si obtuvo beneficios de otras actividades pues el cargo de regidor las ocultaba en la documentación, bien por desconocimiento, o bien por su inexistencia al llevar una vida holgada con las riquezas de su hacienda particular. F. J. Aranda Pérez (1999), 264. 
en ostentar, por una vía desconocida ${ }^{99}$, el cargo de regidor con carácter perpetuo, iniciando una línea familiar con un prestigio social y político mayor, cuyas pautas de comportamiento se mantienen, aunque con ligeros cambios hasta años avanzados del siglo XIX.

\section{A MODO DE EPÍLOGO: EL MANTENIMIENTO DE UNA ÉLITE EN EL SISTEMA LIBERAL}

En este epílogo nos corresponder hablar, aunque de forma breve, acerca de la progenie de Agustín de Gálvez Velasco. Fueron tres los hijos habidos de su matrimonio en 1794: Francisco, Agustín y Antonio de Gálvez Fernández del Pino ${ }^{100}$.

De los tres, fue Francisco el que mantuvo una línea más cercana a la oligarquía municipal, por lo menos durante sus primeros años. Su nómina de puestos fue la más amplia de todo el clan, pudiendo además reconstruir los pasos iniciales en su formación académica. Entre sus primeros méritos recalcar como en 1818 obtuvo una beca en el colegio de San Miguel (Granada) estudiando en dicho emplazamiento lógica, aritmética y álgebra. Durante los dos años siguientes, 1819-1820, lo hizo en ética, metafísica, física y geometría, graduándose de bachiller en filosofía en 1820, de bachiller en leyes en 1822 y convirtiéndose dos años más tarde en abogado tras ser examinado y aprobado por la Chancillería de Granada. Con la referida carrera pasó a ostentar el cargo de alcalde mayor en la villa de Gaucín $^{101}$, mientras que para la fecha de 1832 aparece ya como miembro del Consejo de Su Majestad siendo alcalde del crimen de la Real Audiencia de Extremadura ${ }^{102}$.

Por otra parte, su hermano Agustín, que llegó a ser miembro de la Orden de Carlos III e Isabel la Católica y Secretario de Su Majestad, tuvo una carrera más cercana con la actividad hacendística siendo comandante

99. Sobre la consecución del oficio de regidor véase F. Tomás y Valiente (1975).

100. Ante la imposibilidad de localizar el testamento de Agustín de Gálvez Velasco conocemos su descendencia a través del testamento de su hermana Francisca. AHMA, escribanía de Miguel de Talavera y Toro, leg. 2428, fol. 586v. Testamento de Francisca de Gálvez Velasco, 20 de noviembre de 1830.

101. AHN, Consejos, C. 12101, Exp. 64, fols. 1-2. Relación de los méritos literarios de don Francisco de Gálvez y Fernández, 1829.

102. AHMA, escribanía de Miguel de Talavera y Toro, leg. 2430, fol. 368v. Partición de bienes de Francisca de Gálvez Velasco, 8 de junio de 1832. Aparece además en la lista de decano del Ilustre Colegio de Abogados de Antequera entre 1868-1876. 
del resguardo de la Laguna de Fuente de Piedra y administrador de Rentas Estancadas de Antequera ${ }^{103}$.

Como se puede observar, el posicionamiento político de su padre como regidor posibilitó un empuje en la carrera de sus respectivos hijos, llegando a integrarse en los órganos del gobierno de la monarquía ${ }^{104}$. No parece que se mantuviera el uso de la regiduría, pero la posición social se consolidó, como demuestra la estrategia matrimonial seguida por Agustín de Gálvez con respecto a la que fue su única hija, María del Rosario de Gálvez y Muñoz de Sotomayor que contrajo matrimonio con Juan de Dios Pareja y Aguayo, hijo, aunque no primogénito, del V conde de la Camorra, Francisco Pareja y su mujer, Dolores Aguayo Bermuy ${ }^{105}$. Los Gálvez, tras casi doscientos años de andadura, enlazaban desde una posición más aventajada con la nobleza titulada ${ }^{106}$.

Si bien no todas las trayectorias familiares supusieron el ascenso, lo cierto es que este linaje supo adaptarse y beneficiarse a los momentos de cambio, en buena medida y como se ha podido observar, fruto de su concienzuda política nupcial y de su integración en la administración hispánica mediante su formación universitaria.

\section{CONCLUSIONES}

Muchos son los nombres, los documentos y las familias que quedan todavía por sacar a la luz dentro de la sociedad antequerana de la Edad Moderna. Con el presente trabajo hemos pretendido realizar un pequeño aporte a lo que creemos un campo demasiado inexplorado para la zona, el

103. AHN, FC-M ${ }^{\circ}$ Hacienda, C. 3760, Exp. 17, s.f. Expediente de Agustín de Gálvez Fernández del Pino, 1847. Pese a que no conocemos la fecha exacta de la muerte de Agustín de Gálvez se podría pensar que esta ocurrió entre los últimos años de los años 70 y principios de los 80 .

104. Destacamos al tercero de los hijos, Antonio, que también ejerció en algunos cargos de la administración. AHN, FC-M﹎Hacienda, C. 3760, Exp. 18, s.f. Aunque no hablamos de una oligarquía propiamente dicha pues parece que se aparta de los órganos del poder concejil, si se mantienen como élite social, interesante ver el proceso en otros municipios como el caso de Santiago de Compostela. M. López Díaz (2007).

105. AHMA, Archivo de los Condes de la Camorra, C. 183, carp. 1, s.f. Testamento de Agustín de Gálvez Fernández del Pino, 28 de diciembre de 1870.

106. Posiblemente estemos hablando de un enlace entre una familia noble y otra que, aunque integrante de los privilegiados estuvo más cercana, por los puestos en la administración, con la burguesía local. Pese a ello, nos los encontramos entre los diez mayores contribuyentes de Antequera durante el siglo XIX. A. Parejo Barranco (1998), 146-147. 
análisis de la trayectoria de una familia importante desde inicios del siglo XVIII al siglo XIX.

Tras el desarrollo de todo el aparato analítico hemos podido comprobar cuáles fueron los orígenes socioeconómicos del linaje de interés, recogiendo en buena medida aquella propuesta que, hace unos años, lanzaban Gutiérrez Núñez e Ybáñez Worboys cuando hablando sobre el llamamiento de nobles de 1706 expusieron el interés radicado en el estudio de las familias insertas en el padrón, tratando de dilucidar cuáles fueron las consecuencias, al fin y al cabo, de la contienda a un nivel microanalítico y en una larga duración.

En el caso de los Gálvez, y a falta de conocer parte de la proyección de sus antepasados en tierras sevillanas, la hidalguía derivada de dicha circunstancia puso una de las primeras piedras en la construcción de su posicionamiento, aunque sin desdeñar que la herencia recibida por el primero de sus miembros en tierras antequeranas fuera un aliciente idóneo para el inicio de su andadura por la senda del ascenso social.

Como se ha podido ver, la mayor baza en cuando al ascenso de las generaciones vino dada por unas estrategias matrimoniales planteadas con excelente inteligencia y que plasmaron una conducta aristocrática, pues el primero de los enlaces entre Francisco de Gálvez y Juana de Montoya los unía con la heredera de un mayorazgo. Con ello, los Gálvez pasaban de ser unos burgueses locales a poseer un vínculo que favoreció más que al mantenimiento de unos niveles de riqueza elevados, a la perpetuación de la memoria familiar a través de las generaciones, la nobleza se medía, por lo tanto, como un comportamiento social.

La introducción en el cabildo municipal amplió de forma considerable las posibilidades en cuanto a las estrategias nupciales, contando además con la posesión de un vínculo, nunca más en manos de una mujer, que permitió mayor capacidad electiva. En dicha posición, una de las cuestiones de mayor interés ha sido plantear el mundo de los escribanos como una capa baja entre las oligarquías locales, aunque con gran movilidad; sus amplias funciones tanto fuera como dentro de la vida pública les ofreció un gran reconocimiento entre sus conciudadanos. En este sentido, la formación universitaria obtenida por algunos miembros del clan les sirvió para introducirse en los resortes de la administración de la monarquía. Un hecho que viene a coincidir con el seguido por otras muchas familias de hidalguía media-baja que crecieron gracias a la preparación académica, en detrimento de una nobleza titulada aletargada por sus sempiternos privilegios.

Como hidalgos, los Gálvez Velasco dieron un paso más en la pirámide de los privilegiados, pasando de las capas bajas a posicionarse entre las 
medias. El deseado hábito de una orden llegaba en unos momentos de gran incertidumbre para la Corona, tras pasar por una contienda contra los franceses la monarquía decidió premiar a aquellos que permanecieron fieles al rey, sólo así se explica el aumento de concesiones de cruces, como hemos podido ver, a partir de 1814.

Junto con esta nobleza más consolidada, se producía la toma verdadera del poder municipal por parte de otros miembros, la regiduría perpetua recaía sobre uno de sus integrantes y con ello las posibilidades, como pasaría finalmente, de llegar a la política estatal y una vez allí la unión, de nuevo, mediante matrimonio con una casa titulada.

Los Gálvez, como les ocurriría a otras tantas familias, se aprovecharon principalmente de tres cuestiones para su ascenso: las necesidades de la monarquía en sus momentos de debilidad, las posibilidades ofrecidas por la política local y la naturaleza provinciana de su nobleza titulada para el caso de Antequera. Estas fueron las claves que les llevaron a pasar de ser unos hidalgos artesanos a partícipes de los devenires políticos de una de las ciudades más relevantes del centro andaluz.

Por último, repetir que el presente estudio trata tan sólo de arrojar algo de luz a un vacío historiográfico que urge llenar. La relevancia de Antequera hace necesario afrontar un análisis pormenorizado de su cabildo y de las familias integradas en él, al modo que fue estudiado el gobierno municipal veleño. Con esto, podrían observarse grandes similitudes e, incluso, cruces familiares entre aquellos que ostentaron el poder en los principales centros de la provincia, a la sazón: Málaga, Vélez-Málaga, Marbella, Ronda y Antequera y explicar, asimismo, los orígenes del sistema liberal, ya adentrados en la centuria decimonónica, de los ayuntamientos malagueños. 


\section{ANEXO: ÁRBOL GENEALÓGICO DE LA FAMILIA GÁLVEZ}

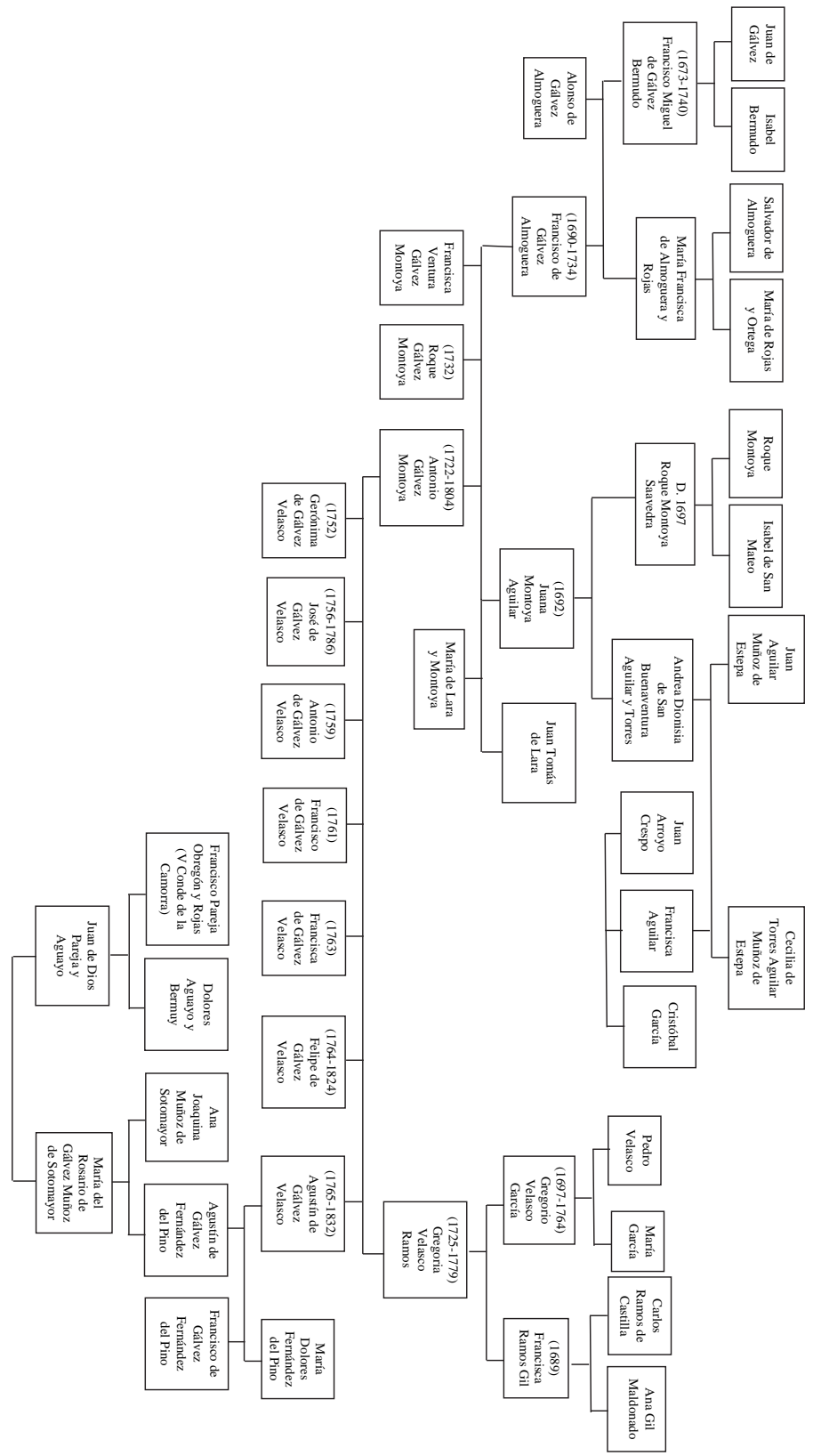

Fuente: elaboración propia. Documentación notarial del AHMA. 


\section{BIBLIOGRAFÍA}

Alfani, Guido y Gourdon, Vincent (2006), “Las familias y la elección de padrinos y madrinas de bautizo en la Europa católica en la Edad Moderna. Balance y perspectivas de investigación”, Revista de Historia Moderna. Anales de la Universidad de Alicante, 34, pp. 23-42.

Álvarez de Morales, Antonio (1985), La ilustración y la reforma de la Universidad en la España del siglo XVIII, Pegaso, Madrid.

Aranda Pérez, Francisco José (1999), Poder y poderes en la ciudad de Toledo. Gobierno, sociedad y oligarquías en la Edad Moderna, Universidad de Castilla-La Mancha, Cuenca.

Arroyal Espigares, Pedro José; Martín Palma, María Teresa y Cruces Blanco, Esther (1991), Las escribanías públicas de Málaga (1487-1516), Universidad, Málaga.

Birriel SALcedo, Margarita (2008), “El cónyuge supérstite en el derecho hispano”, Chronica Nova, 34, pp. 13-44.

Bravo Lozano, Jesús (1992), Familia busca vivienda. Madrid, 1670-1700, Fundación Matritense del Notariado, Málaga.

Ceballos-Escalera y Gila, Alfonso de (2016), La Real y Distinguida Orden Española de Carlos III, Presidencia del Gobierno, Real Casa de la Moneda y Boletín Oficial del Estado, Madrid.

ChAcón JimÉnez, Francisco (2007), "Familia, casa y hogar. Una aproximación a la definición y realidad de la organización social española (siglos XIII-XX)”, en F. Chacón Jiménez y J. Hernández Franco (eds.), Espacios sociales, universos familiares. La familia en la historiografía española, Universidad, Murcia, pp. 51-66.

Clavero Salvador, Bartolomé (1974), Mayorazgo, propiedad feudal en Castilla (1369-1836), Siglo XXI, Madrid.

Díaz Álvarez, Juan (2004), “Aproximación al patrimonio económico de la oligarquía municipal ovetense en el tránsito de los siglos XVI al XVII”, en M. A. Faya Díaz (coord.), La nobleza en la Asturias del Antiguo Régimen, Oviedo, KRK, pp. 83-102.

Escalante JimÉnez, José (2016), Los escribanos en Antequera (1478-1869), ExLibric, Málaga.

Esteves Santamaría, María del Pilar (2000), “Transmisiones de escribanías en Madrid (Siglos XVI-XIX)”, Cuadernos de Historia del Derecho, 7, pp. 129-159.

FAya Díaz, María Ángeles (coord.) (2004), La nobleza en la Asturias del Antiguo Régimen, KRK, Oviedo.

- (coord.) (2014), Las ciudades españolas en la Edad Moderna: oligarquías urbanas y gobierno municipal, KRK, Oviedo.

Faya Díaz, María Ángeles y Anes Fernández, Lidia (2007), Nobleza y poder en la Asturias del Antiguo Régimen, KRK, Oviedo.

García de Yegros, Alonso (1915), Historia de la antigüedad y nobleza de la ciudad de Antequera en la provincia de Andalucía. Relación de sus privilegios 
y libertades, con la inscripción de las piedras y epitafios romanos que en ella hay, y su conquista hecha por el Infante Don Fernando y otras muchas noticias, El Siglo XX, Antequera.

García GonzÁlez, Francisco (2007), "La edad y el curso de la vida. El estudio de las trayectorias vitales y familiares como espejo social del pasado”, en F. Chacón Jiménez; J. Hernández Franco y F. García González (eds.), Familia y organización social en Europa y América, siglos $X V-X X$, Editum, Murcia.

García Guillén, Bartolomé (2009), “Las redes familiares como fórmula de oligarquización en una villa de la Hoya de Málaga”, en J. J. Bravo Caro y J. Sanz Sampelayo (eds.), Población y grupos sociales en el Antiguo Régimen. IX Reunión Científica de la Fundación Española de Historia Moderna. Universidad de Málaga (Málaga, 7-9 de junio de 2006), vol. 1, Área de Historia Moderna de la Universidad de Málaga, Málaga, pp. 649-659.

GonzÁlez SÁnchez, Irma (2004), "Patrimonio económico de la nobleza en el Gijón del siglo XVIII”, en M. A. FAyA Día (coord.), La nobleza en la Asturias del Antiguo Régimen, Oviedo, KRK, pp. 199-220.

Gutiérrez Nieto, Francisco Javier e Ybáñez Worboys, Pilar (2007), "El llamamiento a la nobleza de las «dos Andalucías» de 1706”, Revista de Historia Moderna, 25, pp. 53-87.

Hernández Benítez, Mauro (1995), A la sombra de la Corona. Poder local y oligarquía urbana (Madrid, 1606-1808), Siglo XXI, Madrid.

Hernández Franco, Juan y Molina Puche, Sebastián (2011), "La sangre en la familia y su proceso socioinstitucional. Siglos XVI-XVII”, en F. Chacón Jiménez y J. Bestard Camps (dirs.), Familias. Historia de la sociedad española (del final de la Edad Media a nuestros días), Cátedra, Madrid, pp. 113-156.

Hidalgo Fernández, Francisco (2019), "Los Gálvez: la trayectoria social de una familia de plateros en la Antequera del siglo XVIII”, Vínculos de Historia, 8, en prensa.

Imízcoz Beunza, José María y Chaparro Sainz, Álvaro (eds.) (2013), Educación, redes y producción de élites en el siglo XVIII, Sílex, Madrid.

Kagan, Richard (1981), Universidad en la España moderna, Tecnos, Madrid.

López DíAz, María (1993), Goberno municipal e administración local na Galicia do antigo réxime: organización política e estructura interna dos concellos de Santiago e Lugo, Xunta de Galicia, Santiago de Compostela.

- (2007), "Del ayuntamiento borbónico al primer municipio constitucional: el caso de Santiago de Compostela”, Revista de Historia Moderna, 25, pp. 331-358.

— (2013), “"Pequeña nobleza» e instituciones de gobierno: una mirada desde los concejos urbanos gallegos (siglos XVII-XVIII)”, Estudis. Revista de Historia Moderna, 39, pp. 129-151.

- (2014), "Espacios y redes de sociabilidad de las oligarquías urbanas en la Galicia moderna: avances y propuestas de estudio”, Obradoiro de Historia Moderna, 23, pp. 149-183. 
- (2016), Galicia y la instauración de la Monarquía borbónica: poder, élites y dinámica política, Sílex, Madrid.

Molas i Ribalta, Pere (1996), “Els cavallers catalans de l’Orde de Carles III”, Pedralbes, 16, pp. 61-95.

- (1999), “Caballeros valencianos en la orden de Carlos III”, Estudis: Revista de historia moderna, 25, pp. 231-244.

Moutoukias, Zacarías (2002), "Las formas de la acción política: justicia corporativa, faccionalismo y redes sociales (Buenos Aires, 1750-1760)”, Anuario de Historia de América Latina, 39, pp. 69-102.

Moral Roncal, Antonio Manuel (1998), Gremios e Ilustración en Madrid (17751836), Actas, Madrid.

Nausia Pimoulier, Amaia (1998), “Las viudas y las segundas nupcias en la España moderna: últimas aportaciones”, Memoria y Civilización, 9, pp. 233-260.

Parejo Barranco, José Antonio (1985), Antequera en el siglo XVIII (Población, economía y sociedad), Diputación Provincial, Madrid.

- (1998), "Revolución liberal y élites locales. Dos ejemplos antequeranos de la segunda mitad del siglo XIX”, en A. Gómez Mendoza y J. A. Parejo BARRANCo (eds.), De economía e historia: estudios en homenaje a José Antonio Muñoz Rojas, Diputación Provincial, Málaga, pp. 139-184.

Pérez García, Manuel (2009), “Familia, mayorazgo y reproducción social en la oligarquía murciana: aproximación a través de las redes sociales (siglos XVI-XVIII)”, en J. J. Bravo Caro y J. Sanz Sampelayo (eds.), Población y grupos sociales en el Antiguo Régimen. IX Reunión Científica de la Fundación Española de Historia Moderna. Universidad de Málaga (Málaga, 7-9 de junio de 2006), vol. 2, Área de Historia Moderna de la Universidad de Málaga, Málaga, pp. 1115-1122.

PÉrez León, Jorge (2010), “El fraude de la hidalguía: intrusiones en el estado de hijosdalgo durante el siglo XVIII”, Estudios Humanísticos. Historia, 9, pp. 121-141.

Pezzi Cristóbal, Pilar (1995), “El precio de la máquina burocrática. Salarios y gastos administrativos en el cabildo de Vélez-Málaga”, Baetica. Estudios de Arte, Geografía e Historia, 17, pp. 421-436.

- (2003a), El gobierno municipal de Vélez Málaga en el siglo XVIIII, Diputación Provincial, Málaga.

- (2003b), Pasa y limón para los países del norte: economía fiscalidad en VélezMálaga en el siglo XVIII, Universidad, Málaga.

- (2006), “Desenterrando los huesos de cada uno en un susurro. Una averiguación nobiliar para la oligarquía veleña del setecientos”, en Estudios de historia moderna: homenaje a la doctora María Isabel Pérez de Colosía Rodríguez, Universidad, Málaga.

- (2017), "Poder, cambio generacional y encumbramiento social: la familia Piédrola de Vélez-Málaga en el siglo XVIII”, en J. F. HenAREJos LóPEz y A. Irigoyen López (eds.), Escenario de familia: trayectorias, estrategias y pautas culturales, siglos XVI-XX, Editum, Murcia, pp. 57-68. 
Quintana Toret, Francisco Javier y Pereiro Barbero, María Presentación (1986), "Los regidores perpetuos del concejo malagueño bajo los Asturias (1517-1700). Origen y consolidación de un grupo oligárquico”, Jábega, 56, pp. 43-63.

Reder Gadow, Marion (1982), "Breve estudio sobre los Escribanos Públicos malagueños a comienzos del siglo XVIII”, Baetica. Estudios de Arte, Geografía e Historia, 5, pp. 195-205.

- (1997), "La perpetuación de un linaje en el municipio malagueño: los regidores Pizarro (siglos XVI-XIX)”, en J. Casey y J. Hernández Franco (dirs.), Familia, parentesco y linaje: Congreso Internacional de Historia de la Familia. Nuevas perspectivas sobre la sociedad europea. Murcia 1994, Universidad, Murcia, pp. 99-110.

Rodríguez Alemán, Isabel (2008), “Opciones matrimoniales de la mujer viuda en Málaga (1564-1700)”, Chronica Nova, 34, pp. 91-122.

Rodríguez-San Pedro Bezares, Luis Enrique (2002), “Universidad de la Monarquía Católica, 1555-1700”, en L. E. Rodríguez-San Pedro Bezares (coord.), Historia de la Universidad de Salamanca, vol. I: Trayectoria histórica e instituciones vinculadas, Universidad, Salamanca, pp. 97-146.

Ruiz Ortega, José (1955), Así es Antequera, Diputación Provincial, Málaga.

Ruiz Povedano, José María (1989), Poder y sociedad en Málaga. La formación de la oligarquía ciudadana a fines del siglo XV, Diputación Provincial, Málaga.

SÁNCHEz GARcíA, Miguel Ángel (2014), “El factor familiar y las profesiones sanitarias en el mundo rural. Las tierras de Albacete en el siglo XVIII”, Tiempos Modernos, vol. 8, 29, 1-28.

Sánchez-Granjel Santander, Mercedes (2009), "Médicos y élites locales en la sociedad extremeña del siglo XVIII”, Llull: Revista de la Sociedad Española de Historia de las Ciencias y de las Técnicas, vol. 32, 70, pp. 317-346.

SÁnchez-Lafuente Gemar, Rafael (1997), El Arte de la Platería en Málaga, 15501800, Universidad, Málaga

Soria Mesa, Enrique (2000), “Los estudios sobre las oligarquías municipales en la Castilla moderna. Un balance claroscuro”, Manuscrits, 18, pp. 185-197.

- (2004), “Genealogía y poder. Invención de la memoria y ascenso social en la España moderna”, Estudis, 30, pp. 21-55.

Tomás y VAliente, Francisco (1975), "Las ventas de oficios de regidores y la formación de oligarquías urbanas en Castilla (siglos XVII y XVIII)”, en Actas de las I Jornadas de Metodología Aplicada de las Ciencias Históricas, vol. 3: Metodología de la historia moderna: economía y demografía, Universidad, Santiago de Compostela, pp. 525-547.

Villas Tinoco, Siro (1979), Málaga en tiempos de la revolución francesa, Universidad, Málaga.

- (1996), Estudio sobre el Cabildo Municipal Malagueño en la Edad Moderna, Diputación Provincial, Málaga

Vivas de Montoya y Bexines, Juan (1731), Sermon polyticio moral, que en la oposicion a la Canongia Lectoral de Escritura de la Santa Iglesia de An- 
tequera, dixo el doctor don Juan Vivas de Montoya t Bexines, Prebendado de la Santa Iglesia Cathedral de Malaga, este presente año de 1731. Sacale a luz el doctor D. Francisco de Gálvez y Almoguera, Medico de Honor con exercicio de la Real Casa, y Familia de su Magestad. Y la dedica a la serenissima reyna de los Angeles Maria, en el Triunfante Mysterio de su Gloriosissima Assumpcion, s. n., s. l.

YвÁÑEz Worboys, Pilar (2002), “Alcaldes mayores malagueños (1700-1725)”, en J. L. Pereira Iglesias (coord.), Felipe V de Borbón 1701-1746: actas del Congreso de San Fernando (Cádiz) de 27 de noviembre a 1 de diciembre de 2000, Universidad de Córdoba y Ayuntamiento de San Fernando, Córdoba y San Fernando, pp. 235-248.

- (2004), "Las escribanías públicas del número en Málaga durante la etapa carolina”, Baetica. Estudios de Arte, Geografía e Historia, 26, pp. 389-406. 